\title{
Ketoacidotic crisis after vaccination in a girl with beta-ketothiolase deficiency: a case report
}

\author{
Shujiong Mao ${ }^{1}$, Lili Yang ${ }^{2}$, Xiaoshan Yin ${ }^{3}$, Jianbin Yang ${ }^{2}$, Xinwen Huang $^{2}$ \\ ${ }^{1}$ Department of Pediatrics, Affiliated Hangzhou First People's Hospital, Zhejiang University School of Medicine, Hangzhou, China; ${ }^{2}$ Department \\ of Genetics and Metabolism, Children's Hospital, Zhejiang University School of Medicine, National Clinical Research Center for Child Health, \\ Hangzhou, China; ${ }^{3}$ School of Health in Social Science, The University of Edinburgh, Edinburgh, UK \\ Correspondence to: Xinwen Huang, MD. Department of Genetics and Metabolism, Children's Hospital, Zhejiang University School of Medicine, \\ National Clinical Research Center for Child Health, 3333 Binsheng Road, Hangzhou 310052, China. Email: 6305022@zju.edu.cn.
}

\begin{abstract}
Beta-ketothiolase (mitochondrial acetoacetyl-CoA thiolase, T2) is a rare autosomal recessive disease caused by ACAT1 gene pathogenic variant involving isoleucine catabolism and ketone body metabolism disorder. The onset of ketoacidotic crisis commonly follows prior concurrent diseases or triggers including long-time fasting, infections, intake of high-level of lipids or proteins, etc. A girl aged 8 months presented with fever and cough on the day after vaccination of the second dose of Japanese encephalitis inactivated; on the second day after vaccination, she was admitted to the local hospital because of unconsciousness and dyspnea. After 1 day of treatment at the local hospital, she was referred to our hospital due to exacerbated conditions including unconsciousness and convulsion. When referring to our hospital, she had metabolic acidosis, hypokalemia, hypernatremia, hyperammonemia, and a Glasgow coma scale of 8 and Kussmaul breathing. Five percent $\mathrm{NaHCO}_{3}(24 \mathrm{~mL} / \mathrm{kg}$ ), glucose and insulin (4-6 g glucose/1 U insulin) were continuously infused for correcting acidosis. L-carnitine $(350 \mathrm{mg} / \mathrm{kg} / \mathrm{day})$ was given for ensuring the energy and increasing exudates of metabolites after admission. Protein was limited at $1.5 \mathrm{~g} / \mathrm{kg} /$ day. Mechanical ventilation support and hemodialysis were used. The patient was still under unconsciousness after 2 weeks of intensive treatment in the Pediatric Intensive Care Unit (PICU). Due to her severe illness, the child's parents ultimately decided to redirect their goals of care, and the child was discharged home where she died. For children with acute unexplainable metabolic acidosis, differential diagnosis of T2 deficiency should be considered. Rigorous indicative treatments including mechanical ventilation and hemodialysis should be given timely if ketoacidotic crisis occurred in patients with T2 deficiency.
\end{abstract}

Keywords: Ketoacidotic crisis; vaccination; beta-ketothiolase deficiency; case report

Submitted Aug 26, 2020. Accepted for publication Dec 18, 2020.

doi: $10.21037 /$ tp-20-265

View this article at: http://dx.doi.org/10.21037/tp-20-265

\section{Introduction}

Beta-ketothiolase (mitochondrial acetoacetyl-CoA thiolase, T2) is a rare autosomal recessive disease caused by ACAT1 gene pathogenic variant involving isoleucine catabolism and ketone body metabolism disorder (1-4). Clinical presentations vary in patients with beta-ketothiolase deficiency from mild or no symptoms to severe recurrent episodes of ketoacidotic crises. The triggers to ketoacidotic crises include long-time fasting, infections, intake of high-level of lipids or proteins, etc. (4). Characteristic laboratory findings include significant ketonuria, increased urine 2-methyl-3-hydroxybutyric acid (2M3HB), 2-methylacetoacetic acid (2MAcAc), and tiglylglycine (TG), and elevated blood levels of tiglylcarnitine (C5:1) and 2-methyl-3-hydroxybutyryl-carnitine (C5-OH) carnitines (2-4).

For pediatricians, T2 deficiency should be considered as a differential diagnosis in patients with severe metabolic acidosis even in regions where T2 deficiency is covered by newborn screening (NBS) program (4). Herein, we aimed to 
report a case of T2 deficiency with ketoacidotic crisis after vaccination against Japanese encephalitis. We also reviewed the literature and focused on discussing the triggers of ketoacidotic crises in T2 deficiency and how to prevent and manage ketoacidotic crisis in these patients.

We present the following article in accordance with the CARE reporting checklist (available at http://dx.doi. org/10.21037/tp-20-265).

\section{Case presentation}

An 8-month-old female infant was admitted to this hospital because of unconsciousness and convulsion.

The patient has been well until 3 days before this admission, when fever and cough occurred on the day after vaccination of the second dose of Japanese encephalitis inactivated. Antipyretic and cough medicine were administrated to the patient. On the second day, the patient developed to unconsciousness and dyspnea suddenly at home. She was then admitted to the local hospital in emergency. Laboratory examination revealed a severe metabolic acidosis $(\mathrm{pH}=6.98$, $\mathrm{BE}=-28 \mathrm{mmol} / \mathrm{L}, \mathrm{HCO}_{3}=2.7 \mathrm{mmol} / \mathrm{L}$ ), electrolyte imbalance $\left(\mathrm{K}^{+}=2.6 \mathrm{mmol} / \mathrm{L}, \mathrm{Na}=152 \mathrm{mmol} / \mathrm{L}\right.$, ammonia $\left.=109 \mu \mathrm{mol} / \mathrm{L}\right)$ and hyperglycemia $(10.72 \mathrm{mmol} / \mathrm{L})$. After 1 day of treatment at the local hospital, she was referred to our hospital due to exacerbated conditions including unconsciousness and convulsion. Upon admission at our hospital, she had metabolic acidosis, hypokalemia, hypernatremia, hyperammonemia, and a Glasgow coma scale of eight and Kussmaul breathing. Blood acylcarnitine analysis showed high levels of $\mathrm{C} 5: 1$ and $\mathrm{C} 5-\mathrm{OH}$ at $1.22 \mu \mathrm{mol} / \mathrm{L}$ (ref: $<0.05$ ) and $1.42 \mu \mathrm{mol} / \mathrm{L}$ (ref: <0.44), respectively. Gas chromatographymass spectrometer (GC/MS) analysis revealed a high level of $2 \mathrm{M} 3 \mathrm{HB}$ at $(43.71 \mathrm{mmol} / \mathrm{mol}$ creatinine, ref: $<0.014)$ and TG $53.85 \mathrm{mmol} / \mathrm{mol}$ creatinine (ref: $<0.001$ ). The results revealed that the patient had a homozygous pathogenic variant of c.121-3C>G (splicing error) in the ACAT1 gene. Based on the laboratory and genetic results, the patient was diagnosed with $\mathrm{T} 2$ deficiency. Five percent $\mathrm{NaHCO}_{3}$ $(24 \mathrm{~mL} / \mathrm{kg})$, glucose and insulin (4-6 g glucose/1 U insulin) were continuously infused for correcting acidosis. L-carnitine (350 mg/kg/day) was given for ensuring the energy and increasing exudates of metabolites after admission. Protein was limited at $1.5 \mathrm{~g} / \mathrm{kg} /$ day. Mechanical ventilation support and hemodialysis were used. The patient was still under the state of unconsciousness after 2 weeks of intensive treatments in our Pediatric Intensive Care Unit (PICU). Due to her severe illness, the child's parents ultimately decided to redirect their goals of care and the child was discharged home, where she died.

This study was approved by the Ethical Committee of Children's Hospital, Zhejiang University School of Medicine (2017-IRB-034). All procedures performed in studies involving human participants were in accordance with the ethical standards of the institutional and/or national research committee(s) and with the Helsinki Declaration (as revised in 2013). Written informed consent was obtained from the patient's parents.

\section{Discussion}

$\mathrm{T} 2$ is important in ketogenesis both in the hepatic and extrahepatic tissues (4); in extrahepatic tissues, T2 is important in ketolysis which catalyzes predominantly acetoacetyl-CoA cleavage to form acetyl-CoA. Another thiolase, mitochondrial 3-ketoacyl-CoA thiolase, which can compensate for T2 deficiency in ketogenesis but to a lesser extent in ketolysis (2-4). Therefore, T2 deficiency leads to ketosis. In most cases with T2 deficiency, the first ketoacidotic episode is commonly very severe following conditions under ketogenic stresses, especially gastroenteritis or respiratory diseases in association with fasting and catabolic conditions (4). In T2 deficiency, catabolic conditions appear to confer a higher risk than that of protein overload. In the reports of five large series from India, Vietnam, France, Japan, Turkey, Germany and Ireland (2,3,5-7), triggers of the ketoacidotic crisis were commonly infections including gastroenteritis or respiratory infections; and only one case was trigged by excessive protein intake (Table 1). Literature review in the Chinese patients also revealed that infections were common triggers for ketoacidotic crisis $(8-12,14)$; three patients in a family with two twin boys and their sister had disease onset after transition from breastfeeding to highprotein milk formula feeding (13). Our case is the first case with ketoacidotic crisis occurring after vaccination. This case in the other side reflects the importance of NBS. The appropriate precautions could be taken if the disorder was diagnosed by NBS prior to vaccination for preventing the fatal ketoacidotic crisis. We should attach importance to vaccination in the patients with inborn errors of metabolism (IEM). In general, patients with IEM are not at increased risk of metabolic decompensation following appropriate vaccinations $(15,16)$. We should be very cautious or provide close follow-up for patients after administration of immunizations because some 
Table 1 Triggers of ketoacidotic crisis in symptomatic patients with beta-ketothiolase deficiency

\begin{tabular}{lccl}
\hline Studies & $\begin{array}{c}\text { Number of patients with } \\
\text { ketoacidotic crisis }\end{array}$ & $\begin{array}{c}\text { Number of patients with triggers } \\
\text { prior to ketoacidotic crisis }\end{array}$ & Triggers or concurrent diseases \\
\hline Fukao et al. (5) & 26 & 14 & Gastroenteritis or respiratory illness \\
Abdelkreem et al. (2) & 10 & 8 & Respiratory illness or gastroenteritis \\
Grünert et al. (6) & 32 & 20 & Gastroenteritis or respiratory infections \\
Paquey et al. (7) & 26 & 21 & Infections \\
Nguyen et al. (3) & 41 & 39 & $\begin{array}{l}\text { Gastroenteritis or respiratory infections (38 } \\
\text { cases); excessive protein intake (one cases) }\end{array}$ \\
$\begin{array}{l}\text { Liu et al. (8); Shen et al. (9); } \\
\text { Sun et al. (10); Wang et al. (11); }\end{array}$ & 9 & 9 & $\begin{array}{l}\text { Gastroenteritis or respiratory infections (six } \\
\text { Yue et al. (12); Wen et al. (13) }\end{array}$ \\
\hline
\end{tabular}

inborn errors with associated impaired immune functions or tendency for rapid decompensation (17). Experts also suggest that vaccines based on live attenuated viruses should not be given to IEM (18). Particularly for the IEM patients with concurrent infection, vaccination will enhance the stress condition of the body, and induce or exacerbate the ketoacidosis episode. Our case had an undetected respiratory tract infection before vaccination; the potential infection together with vaccination may have triggered the onset of severe ketoacidotic crisis. The parents therefore filled a death lawsuit against the vaccinator and institution of vaccination. The death and the lawsuit of this case made us propose a procedure of checking temperature before vaccination for all children. Centers for Disease and Prevention of Zhejiang Province adopted the proposition, and now body temperature checking before vaccination becomes a routine procedure in Zhejiang Province.

Intensive treatment of the first acute ketoacidosis episode is imperative for better outcome; continuous infusion of intravenous glucose and electrolytes is recommended which will increase the urine volume for excretion of acids and suppress ketosis (4). Insulin can be infused together with glucose if with hyperglycemia (4). It is important to actively correct acidosis. L-carnitine is recommended to be infused at a dose of $300-500 \mathrm{mg} / \mathrm{kg} /$ day. Timely mechanical ventilation and hemodialysis can also benefit for managing acute ketoacidosis episode, however, it is a challenge for local hospitals where lacking of techniques and equipments. Most patients with T2 deficiency had favorable outcome even with severe ketoacidotic crisis. The lessons learned from our patient were as following: for children with acute metabolic acidosis, T2 deficiency should be considered; rigorous indicative treatments including mechanical ventilation and hemodialysis should be given timely if ketoacidosis occurred in patients with $\mathrm{T} 2$ deficiency.

For the asymptomatic patients or those under nonepisodic conditions, fasting should be avoided (13). Oral $\mathrm{L}$-carnitine is recommended to be supplemented at a dose of $50-200 \mathrm{mg} / \mathrm{kg} /$ day. If patients are under ketogenic conditions, such as vomiting, appetite loss, or infections, sufficient oral glucose supplementation or glucose infusion is recommended for preventing ketoacidotic crisis (2-4). Protein intake is recommended to be restricted to $1.5-2.0 \mathrm{~g} / \mathrm{kg}$ per day for patients when under stable stage from a theoretical standpoint (4). For our asymptomatic patients diagnosed by NBS, we recommend restricting protein intake to $1.5-2.0 \mathrm{~g} / \mathrm{kg} / \mathrm{day}$ for infants and $1.0-1.5 \mathrm{~g} / \mathrm{kg} / \mathrm{day}$ for those aged $\geq 1$ year of age.

In conclusion, $\mathrm{T} 2$ deficiency should be considered as a differential diagnosis in patients with severe metabolic acidosis. Timely rigorous symptomatic treatment should be given to patients under ketoacidotic crisis. For patients with IEM, vaccination should be taken when under well conditions and excluding potential infections. For patients under ketogenic conditions including fasting, respiratory and gastrointestinal infections, sufficient glucose and carnitine should be supplemented for preventing ketoacidotic crisis.

\section{Acknowledgments}

Funding: This study was supported by grants from 2018 National Key Research and Development Program of China (2018YFC1002204), and Health Commission of 
Zhejiang Province (2017KY445).

\section{Footnote}

Reporting Checklist: The authors have completed the CARE reporting checklist. Available at http://dx.doi.org/10.21037/ tp-20-265

Conflicts of Interest: All authors have completed the ICMJE uniform disclosure form (available at http://dx.doi. org/10.21037/tp-20-265). The authors have no conflicts of interest to declare.

Ethical Statement: The authors are accountable for all aspects of the work in ensuring that questions related to the accuracy or integrity of any part of the work are appropriately investigated and resolved. All procedures performed in studies involving human participants were in accordance with the ethical standards of the institutional and/or national research committee(s) and with the Helsinki Declaration (as revised in 2013). Written informed consent was obtained from the patient's parents.

Open Access Statement: This is an Open Access article distributed in accordance with the Creative Commons Attribution-NonCommercial-NoDerivs 4.0 International License (CC BY-NC-ND 4.0), which permits the noncommercial replication and distribution of the article with the strict proviso that no changes or edits are made and the original work is properly cited (including links to both the formal publication through the relevant DOI and the license). See: https://creativecommons.org/licenses/by-nc$\mathrm{nd} / 4.0 \%$.

\section{References}

1. Daum RS, Lamm PH, Mamer OA, et al. A "new" disorder of isoleucine catabolism. Lancet 1971;2:1289-90.

2. Abdelkreem E, Akella RRD, Dave U, et al. Clinical and mutational characterizations of ten Indian patients with beta-ketothiolase deficiency. JIMD Rep 2017;35:59-65.

3. Nguyen KN, Abdelkreem E, Colombo R, et al. Characterization and outcome of 41 patients with beta-ketothiolase deficiency: 10 years' experience of a medical center in northern Vietnam. J Inherit Metab Dis 2017;40:395-401.

4. Fukao T, Sasai H, Aoyama Y, et al. Recent advances in understanding beta-ketothiolase (mitochondrial acetoacetyl-CoA thiolase, T2) deficiency. J Hum Genet 2019;64:99-111.

5. Fukao T, Scriver CR, Kondo N, et al. The clinical phenotype and outcome of mitochondrial acetoacetyl-CoA thiolase deficiency (beta-ketothiolase or T2 deficiency) in 26 enzymatically proved and mutation-defined patients. Mol Genet Metab 2001;72:109-14.

6. Grünert SC, Schmitt RN, Schlatter SM, et al. Clinical presentation and outcome in a series of 32 patients with 2-methylacetoacetyl-coenzyme A thiolase (MAT) deficiency. Mol Genet Metab 2017;122:67-75.

7. Paquay S, Bourillon A, Pichard S, et al. Mitochondrial acetoacetyl-CoA thiolase deficiency: basal ganglia impairment may occur independently of ketoacidosis. J Inherit Metab Dis 2017;40:415-22.

8. Liu J, Qian S. A case of acetoacetate coenzyme A thiolase deficiency. Chinese Journal of Emergency Medicine 2010;19:1065.

9. Shen Y, Li J, Xiao G, et al. beta-ketothiolase deficiencybeta-ketothiolase deficiency in a newborn. Chinese Journal of Birth Health \& Heredity 2016;24:98.

10. Sun L, Song W, Huang X, et al. Beta-ketothiolase deficiency: a case report. Chinese Pediatric Emergency Medicine 2014;21:610-1.

11. Wang $\mathrm{Y}, \mathrm{Ma}$ L. Beta-ketothiolase deficiency in a neonate. Chinese Journal of Practical Pediatrics 2008;23:355.

12. Yue A, Liu F, Zhang H, et al. Beta-ketothiolase deficiency: a case report. Chinese Journal of Practical Pediatrics 2006;21:299.

13. Wen $P$, Chen Z, Wang G, et al. Analysis of clinical phenotype and ACAT1 gene mutation in a family affected with beta-ketothiolase deficiency. Zhonghua Yi Xue Yi Chuan Xue Za Zhi 2016;33:286-91.

14. Li X, Liu L. Beta-ketothiolase deficiency. In: Curable rare diseases. Shanghai: Shanghai Jiao Tong University Press, 2016.

15. Baumgartner MR, Hörster F, Dionisi-Vici C, et al. Proposed guidelines for the diagnosis and management of methylmalonic and propionic acidemia. Orphanet J Rare Dis 2014;9:130.

16. Kingsley JD, Varman M, Chatterjee A, et al. Immunizations for patients with metabolic disorders. Pediatrics 2006;118:e460-70.

17. Klein NP, Aukes L, Lee J, et al. Evaluation of immunization rates and safety among children 
with inborn errors of metabolism. Pediatrics 2011;127:e1139-46.

18. Menni F, Chiarelli G, Sabatini C, et al. Vaccination in children with inborn errors of metabolism. Vaccine 2012;30:7161-4.

Cite this article as: Mao S, Yang L, Yin X, Yang J, Huang X. Ketoacidotic crisis after vaccination in a girl with betaketothiolase deficiency: a case report. Transl Pediatr 2021;10(2):459-463. doi: 10.21037/tp-20-265 